\title{
A importância da mediação escolar como promotora de uma cultura de paz
}

The importance of school mediation as a promoter of a culture of peace

\section{Cristiane de Souza Reis}

Instituto de Estudos Comparados em Administração de Conflitos 
Os conflitos fazem parte da sociedade e não é diferente no contexto escolar, onde as crianças e os jovens deparam-se constantemente com o conflito.

As medidas de administração de conflito, via de regra, são punitivas, disciplinares, corretivas. Recaindo o olhar sobre Portugal, estão estas medidas previstas tanto no Estatuto do Aluno e Ética Escolar, quanto na Lei de Proteção de Crianças e Jovens em Perigo e na Lei Tutelar Educativa. Não raras vezes, a polícia intervém, por meio do programa policial "Escola Segura". Nestes modelos há pouco espaço de diálogo, não se prioriza a empatia, não se tenta compreender e ouvir o outro, e, de fato, administrar o conflito.

O modelo punitivo reforça a violência, enquanto a mediação do conflito como forma de administração, ensina um novo olhar sobre este conflito, fazendo desenvolver na população infanto-juvenil competências positivas em relação à administração do conflito, onde o diálogo e a empatia fazem-se presentes, levando ao desenvolvimento de uma cultura de paz, que favorecerá a construção de uma sociedade mais justa, solidária e igualitária. É justamente a importância desta mudança de paradigma frente à administração de conflito que se pretende demonstrar, por meio de revisão de literatura, neste trabalho.

Palavras-chave: mediação escolar, conflitos, administração de conflitos, punição, cultura de paz.

\section{Abstract}

Conflicts are part of society and it is no different in the school context, where children and youth are constantly faced with conflict.

Conflict management measures, as a rule, are punitive, disciplinary, corrective. Looking back on Portugal, these measures are foreseen both in the Student Statute and School Ethics and in the law for the protection of children and young people in danger and the Educational Guardian Law. Not infrequently, the police intervene, and it is true that there is even a police program for the school: the Safe School. In these models there is little room for dialogue, empathy is not prioritized, there is no attempt to understand and listen to the other, and, in fact, to manage the conflict.

The punitive model reinforces violence, while the mediation of the conflict as a form of administration, teaches a new look at this conflict, making the child and youth population develop positive skills in relation to conflict management, where dialogue and empathy 

Conforme notícia veiculada no jornal Lusa em 30 de janeiro do corrente ano, o professor Alexandre Henriques, que se dedica ao estudo da gestão de conflito escolar e possui uma ferramenta de contagem de ocorrências de violência nas escolas portuguesas, asseverou que em dezoito semanas de aulas, as forças policiais foram chamadas, em média, dezassete vezes por dia às escolas e se somaram vinte e quatro casos de agressões ou ameaças de morte, não estando incluído nestes números aqueles que pedem anonimato.

As contendas ocorrem, via de regra, entre os próprios alunos, e, não raras vezes, acabam os pais assumindo a questão e fazendo uso arbitrário das próprias razões: a conhecida justiça pelas próprias mãos. $E$ claro, casos também entre alunos ou pais e professores ou funcionários, mas não podemos olvidar também desses últimos em relação aos alunos.

Diversos são os conflitos que surgem no contexto escolar e que correspondem ao micro espaço social. Na maior parte das vezes, os conflitos resolvem-se com aplicação das medidas disciplinares, corretivas e sancionatórias previstas na Lei n. ${ }^{\circ}$ 51/2012, de 05 de setembro (Estatuto do Aluno e Ética Escolar), podendo ainda ser encaminhado o caso à Comissão de Protecção de Crianças e Jovens, atento ao disposto na Lei n. ${ }^{\circ} 147 / 99$, de 1 de setembro e na Lei n. ${ }^{\circ} 166 / 99$, de 14 de setembro. Mas seriam estas as formas mais adequadas e eficientes em todos os casos?

Importa referir que nessas medidas disciplinares, corretivas e sancionatórias não há a promoção de um diálogo onde um possa ouvir o outro. E quando afirmo isso, estou a tratar de uma escuta empática e não um mero depoimento, uma inquirição. Há simplesmente um "julgamento versus punição". E em diversos outros textos debrucei-me sobre as finalidades da punição, demonstrando que estas não chegam rigorosamente ao propósito teórico que prometem, qual seja a prevenção e a ressocialização. A única finalidade e consequência até que se faz presente em uma punição é a retribuição, sem mencionar, ainda, na seletividade punitiva reproduzida nesse espaço social da mesma forma como ocorre no nível macro social.

É certo que a finalidade retributiva não é admitida teoricamente em Portugal (diferentemente no Brasil, onde já se admite). No entanto e muito infelizmente ela o é. Praticamente só ela está presente, inclusive.

Como dito acima, a polícia é extremamente requisitada nos casos de conflito escolar. A força policial que se dirige às escolas possui departamentos próprios conhecidos como Escola Segura, tanto da Polícia de Segurança Pública (PSP) quanto da Guarda Nacional Republicana (GNR). Na verdade, muitas das vezes, esses casos poderiam ter um outro caminho.

Segundo Afonso Bento, o Programa Escola Segura nasceu em um contexto em que a veiculação do medo era muito grande. Difundia-se um "sentimento de insegurança, recorrentemente essencializado enquanto receio de uma criminalidade e violência originadas em minorias culturais, étnicas e migratórias" (Bento, 2017, p. 336). Assim, a polícia 
entra neste contexto justamente para afastar aqueles que são considerados indesejados, desordeiros. A lógica neoliberal e dominante sempre foi a de afastamento, de distanciamento, de aumento do fosso social. No entanto, para a construção de uma sociedade mais justa, solidária e igualitária, a escuta ativa e a empatia fazem-se necessárias e é já nos bancos escolares que se deve aprender a resolver os conflitos.

Desta forma, este artigo, centrando o meu olhar sobretudo em Portugal, intenta apresentar a importância da administração de conflitos por meio da mediação no contexto escolar para uma melhor experiência social e um desenvolvimento integral da criança e do jovem, que passam a adquirir desde cedo competências positivas para administração de seus conflitos e que refletirá em sua vida presente e futura, passando a ser um meio de emancipação social e empoderamento. Para tanto, efetivou-se uma revisão de literatura, sobretudo, em pesquisas que analisaram a mediação escolar realizada em escolas públicas em Portugal.

Apesar de, ao falar de escolas, tratarmos tanto das escolas públicas quanto as privadas, em relação às públicas recai uma questão que foge ao escopo deste artigo, que é a problemática e controvérsia que tange a Administração Pública e um dos elementos que caracterizam os processos de mediação: a confidencialidade. Não me debruçarei em relação a este importante aspecto, que é um dos princípios do processo de mediação, e que, quando relacionado à administração pública, pode entrar em reta de colisão com o princípio da publicidade, que é, por sua vez, inerente à administração pública. No entanto, já deixo o registo de que entendo que a confidencialidade em um possível acordo entre as partes em conflito, no caso da mediação escolar, não viole a publicidade dos atos e a necessidade de a comunidade estar a par do acontecimento, até porque envolve crianças e jovens e a lei protege o seu anonimato e a divulgação dos fatos.
A mediação é uma forma de administração de conflitos não adversarial, na qual um terceiro neutro e imparcial, favorece o diálogo rompido entre as partes, de modo que estas possam vir a chegar (ou não) a um acordo sob o que as levou à demanda. Este terceiro, que é o mediador, utiliza-se de diversas técnicas para afastar as posições de cada um dos lados, para alcançar os seus reais interesses, separando, para tanto as pessoas dos problemas (Fisher, Ury \& Patton, 2014). Quando isso ocorre, não raras vezes, percebem que não havia tantas diferenças e que muitos dos seus interesses eram comuns, sendo mais fácil haver um apaziguamento. É desta forma que as pessoas acabam por compreender, depois de ter uma escuta ativa e empática, que o outro não é o seu inimigo, mas antes o seu complemento e espelho. Diferentemente do que ocorreria no tribunal judicial, no qual uma decisão ser-lhes-ia imposta, restando uma sensação de derrota, de injustiça, onde a não compreensão do outro ainda permaneceria, entendem que são agora promotores de sua própria decisão, onde cada um dos lados ganha 
afinal de contas, sobretudo porque percebem que seus interesses até eram semelhantes ou iguais. Assim, a mediação consegue alcançar a verdadeira paz social, que é, afinal, a função social do Direito.

É a mediação um dos mecanismos de administração extrajudicial do conflito, pelo qual as partes, auxiliadas na (re)construção comunicacional, podem elas próprias administrar os seus conflitos (por esta razão diz-se que a mediação é uma via de autocomposição de litígios), alcançando ou não, um acordo, total ou parcial, restaurando as relações sociais anteriores, se assim for o caso, ou, ao menos, reestabelecendo a paz social (que, a nível macro é o principal), posto que as partes em litígios sentem-se contempladas e satisfeitas em seus interesses, e não vencidas em suas demandas.

Há um empoderamento das partes e, em consequência, também a emancipação social das mesmas, na medida em que elas constroem o processo em direção a um diálogo mais fluido e empático, diálogo este que anteriormente encontrava-se, por diversas razões, rompido. Como dito anteriormente, o processo de mediação pode culminar em um acordo entre as partes, que elas mesmas compõem, de forma total ou parcial, ou não. No entanto, há quem compreenda, como Maria Tereza Fonseca Dias (2016), que o principal objetivo da mediação é "o entendimento intersubjetivo do conflito, reconhecendo como êxito da mediação até mesmo o processo que tenha sido concluído sem ajuste, desde que tenha perspassado pelo diálogo entre os participantes".

Estes princípios foram extraídos do link: https://www.infojovem.org.br/infopedia/descubra-e-
Assim, a mediação promove o reverso daquilo que presenciamos em nosso cotidiano, que é a cultura da violência. Propaga uma cultura de paz. A cultura da paz, enquanto movimento, foi oficialmente difundida pela UNESCO (Organização das Nações Unidas para a Educação, a Ciência e a Cultura) em 1999, tendo como mote a prevenção de conjunturas que ameacem a paz e a segurança, estando intimamente ligada à prevenção e à resolução nãoviolenta de conflitos", baseando-se em princípios de tolerância, solidariedade, respeito à vida, aos direitos individuais e ao pluralismo'.

Os princípios estruturantes do processo de mediação, estão dispostos nos seus artigos $3 .^{\circ}$ a $9 .^{\circ}$ da Lei n. ${ }^{\circ}$ 29/2013, de 19 de abril, são: voluntariedade, confidencialidade, igualdade e imparcialidade, independência, competência e responsabilidade, e executoriedade.

O princípio da confidencialidade indica que tudo o que se passa no processo da mediação é sigiloso, tanto em relação aos documentos apresentados, quanto ao que ali é tratado e dito. Como a mediação não esgota o acesso ao Direito, caso as partes não cheguem a acordo e/ou continuem em conflito, podem sempre recorrer ao Tribunal ou à Arbitragem. No entanto, tudo que foi ali utilizado ou mencionado não serve como prova em eventual processo judicial ou arbitral, assim como o mediador ou qualquer pessoa que porventura tenha participado do processo de mediação, não poderá ser testemunha.

Já o princípio da igualdade e da imparcialidade determina que o mediador deve tratar a todos de forma igualitária, de

aprenda/cultura-de-pazl, acedido em 20 de maio de 2020. 
modo que cada parte possa expor a sua versão sobre os fatos e os seus interesses, adotando uma posição neutra. Este princípio liga-se ao Princípio da independência, que preconiza que o(a) mediador(a) deve se manter totalmente independente e "livre de qualquer pressão". Sua posição no processo, como se mencionou, é neutra, tanto em relação aos interesses das partes quanto aos seus próprios interesses, não podendo assim intervir no processo de modo a pender a balança para um lado ou para outro. $\mathrm{O}$ princípio da independência também está intimamente relacionado ao da voluntariedade, posto se o mediador se sentir pressionado por quaisquer das partes ou por forças externas, poderá sempre deixar o processo a qualquer momento.

O princípio da competência aduz que para ser mediador(a), sob a égide desta Lei, incluindo os do sistema público, é necessário a frequência e aprovação em curso de formação certificado pelo Ministério da Justiça para o devido efeito. O princípio da responsabilidade determina que qualquer violação aos princípios básicos legais será civilmente responsável por eventual dano causado.

O acordo firmado em sede de processo de mediação, assinado por mediador(a) que conste da lista do Ministério da Justiça, assume automaticamente força executória, não sendo necessária a homologação judicial do acordo. É o que aduz o princípio da executoriedade.

Já o princípio da voluntariedade significa que para o processo de mediação ocorrer, as partes precisam dar 0 seu consentimento para participar do mesmo e nele continuar. $\mathrm{O}$ princípio da voluntariedade abarca também, como já foi dito, o próprio mediador.
Este princípio também é outro elemento de empoderamento, em conjunto com a possibilidade de as partes elaborarem sua própria decisão para o caso, posto que, da mesma forma que podem começar o processo, podem findá-lo, o que não ocorre no processo judicial, onde não possuem este controlo.

Enfim, como já afirmado, o sucesso de uma mediação não necessariamente cinge-se a chegada de um acordo, mas sobretudo na restauração do diálogo, da comunicação. Para tanto, é de extrema importância a busca de uma comunicação empática entre as partes, facilitada e promovida pelo mediador.

$\mathrm{Na}$ mediação, o mediador pode e deve contribuir para esta abordagem comunicacional por meio da empatia, levando em consideração que cada pessoa é única, que sua própria visão de mundo e o vê com as suas próprias lentes, sendo necessário, desta maneira "emprestar os seus óculos" ao outro ou até não colocar óculos nenhum para compreender a necessidade de se ter uma escuta sem julgamentos e/ou críticas, deixando de lado as visões e pré-conceitos que possuía anteriormente.

Cabe ressaltar também que há várias técnicas possiveis para a alcançar a comunicação empática, sendo certo que, quando estamos diante de crianças e jovens, muitas vezes esse conhecimento passa a ser apreendido pelos mesmos, não só para o conflito que experienciam naquele momento como também podem vir a levar essa nova forma de se comunicar para casa, para a sua vida, incluindo a fase adulta.

Essa é uma das razões pelas quais compreendo que a fase da pré-mediação, na qual o mediador esclarece todos os 
pontos do processo de mediação, é tão importante, posto que nela o mediador esclarece o que é a mediação, já que muitos não conhecem ou tem préjulgamentos equivocados, incluindo os advogados, classe de suma importância ao processo de mediação e aos mediandos. Com a realização desta fase de prémediação, as partes poderão vir a dar o seu assentimento de forma consciente para o prosseguimento do processo de mediação.

Assim, a mediação escolar pode se tornar muito mais do que um instrumento de administração de um conflito de um caso concreto, mas um aprendizado permanente, contribuindo para a construção de um novo indivíduo social que passa a estar inserido em uma cultura de paz.

\section{Os conflitos no âmbito escolar}

Os conflitos estão presentes na sociedade. Fazem parte do cotidiano do ser humano. A grande questão é como administrá-los; é saber reconhecer a si e ao próximo, observando seus próprios gatilhos emocionais, que fazem despoletar os conflitos, assim como descobrir como dialogar com o outro de modo a que ambos os interesses sejam atendidos.

De acordo com Georg Simmel, o conflito nem sempre é negativo. Aduz o autor que o conflito "é um modo de conseguir algum tipo de unidade, ainda que através da aniquilação de uma das partes conflituantes" (Simmel, 1983, p. 122).

Conforme Cristiane Reis (2019),

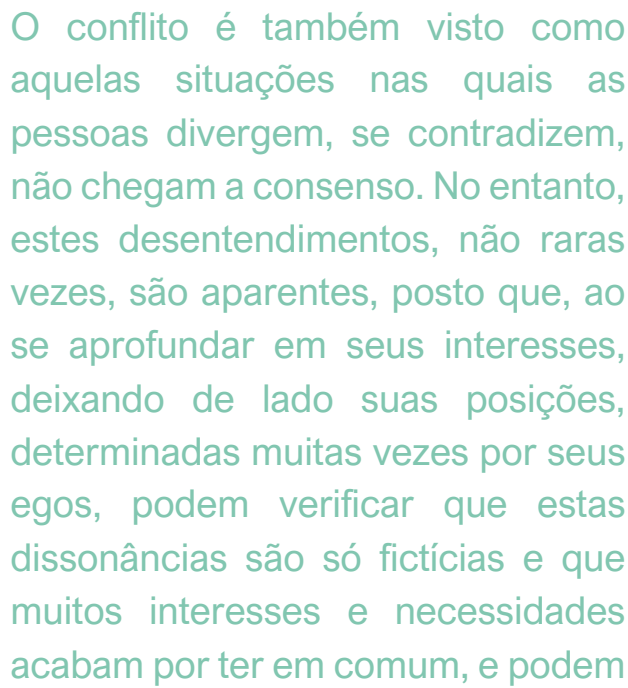

chegar a soluções criativas, vendo suas reais necessidades atendidas, assim como a do outro.

Na seara escolar, vários tipos de conflitos podem ocorrer, desde a indisciplina em sala de aula, em uma relação de poder, como situações de violência, que vai da simbólica a física. Nesse sentido, de acordo com Catarina Tomás,

Os conflitos escolares mais comuns são interpessoais (entre alunos, entre alunos e professores, entre alunos e funcionários), que se transformam em fenómenos emergentes no quotidiano da vida escolar como são o insucesso escolar, o absentismo e o abandono escolar, o bullying, a violência escolar, e a indisciplina na sala de aula. Para além disso, estas situações de conflito ocorrem muitas vezes no plano familiar que, depois, são transportadas e expressas pelas crianças e jovens para o meio escolar (situações de alcoolismo, desemprego, violência doméstica, desresponsabilização parental, entre outras); e também são 


\section{manifestações de violência e incivilidades que emergem nos contextos sociais do meio onde vivem (delinquência, crime, tráfico e consumo de drogas, vandalismo, entre outras). (Tomás, 2010, pp. 21 e 22).}

A indisciplina pode ser considerada menos grave do que a violência, sendo mais relacionada às infrações às regras internas e éticas, ao bom desenvolvimento das aulas, à boa relação entre colegas, entre professores e/ou entre funcionários. Já a violência é considerada mais grave e pode englobar desde a violência verbal, psíquica, como a física. Inclui-se aqui também os casos de bullying.

No entanto, há que se mencionar também os casos em que o jovem pode vir a praticar, por exemplo, um facto tido como típico e ilícito na esfera penal e que não tem violência, como, por exemplo, um furto (no ambiente escolar ou com ele relacionado). Aqui também se instaurou um conflito e que precisa ser administrado.

Uma das formas para se prevenir e até administrar estes conflitos que porventura surjam é a via da mediação, via esta escolhida para este artigo, que intenta promover uma gestão positiva do conflito.

\section{A mediação escolar}

Da mesma forma que conflitos ocorrem na sociedade em geral, igualmente ocorrem no universo escolar. Como já mencionado acima, as medidas adotadas para administrar os conflitos no âmbito escolar são, via de regra, punitivas, sancionatórias. Segundo Pacheco (2006, p. 125), o artigo $26 .^{\circ}$ do Estatuto dos alunos do ensino não superior trata de medidas disciplinares preventivas e integrativas, sendo as sancionatórias as previstas no artigo $27^{\circ}$ do mesmo Diploma legal. O mesmo que também ocorre no nível social macro. No entanto, nem na sociedade em geral, nem no contexto escolar a punição é a melhor solução para se dirimir conflitos.

Teoricamente, a punição, mesmo na seara escolar, vem para (re)validar as normas internas daquele espaço, de modo a que também a penalidade sirva de exemplo tanto para a comunidade (escolar, no caso) quanto para o próprio transgressor da norma, objetivando ressocializar ou reintegrar o indivíduo "recuperado" na esfera social. Há também 0 aspecto retribucionista desta punição (como fez o mal, pune-se com o mal), que, no meu entender, é a única finalidade efetivamente real, mas nada eficaz. Assim, sou defensora não da punição, mas antes da responsabilização, e e esta responsabilização, que começa internamente, que 0 processo de mediação traz, quando as partes se comunicam de forma dialógica e empática.

O conflito, ao menos para já, no momento atual de evolução de nossa sociedade, faz parte da mesma e dele os jovens não escapam também. Se os adultos não sabem, muitas das vezes, lidar com suas emoções, sentimentos, e eclodem litígios, o que dirá as crianças, os adolescentes. As pessoas não aprendem a lidar com as suas emoções e sentimentos; não aprendem a ter empatia, não aprendem a gerir conflitos. Tudo isso devia fazer parte do currículo escolar; da própria formação do indivíduo enquanto ser integral. 
Para o sucesso das ações, e para de modo preventivo tentar evitar alguns conflitos, todos precisam se adequar, incluindo a escola que, via de regra, trata todos os alunos como tendo origens iguais. No entanto, não o são. São pessoas com características diferentes, desejos, necessidades, origens socio-economicoculturais diversas. Enfim, não é possível que se linearize e padronize necessidades, interesses e comportamentos, para após julgar e punir, rotulando (Andrade, 2004; Baratta, 1994, 1999) e disciplinando (Foucault, 1987) as crianças e jovens. Mais uma vez, o processo de mediação ganha vantagens sobre $\mathrm{o}$ modelo punitivo $\mathrm{e}$ sancionatório.

A mediação escolar surge em Portugal em 1999 enquanto meio alternativo de administração de conflito, sendo o primeiro projeto conhecido por Projeto GESPOSIT, que decorreu no ano letivo de 2000/2001. Tal projeto tinha por escopo a "investigação, formação, inovação e intervenção em contexto escolar e familiar" (Pacheco, 2006, p. 142) por meio da mediação e objetivava igualmente o "intercâmbio entre as escolas dos diferentes países participantes (Bélgica, França, Irlanda, Itália, Espanha e Portugal) e entre as doze instituições que colaboraram nesta iniciativa (em Portugal, a Universidade Aberta)" (idem, ibidem).

Este projeto compreendia que a violência na escola era um dos causadores do abandono escolar, para além de assim também se alcançar uma comunicação mais eficaz entre a escola e a família. "Era também promovida uma nova cultura de negociação e consenso na escola, na família e na comunidade" (Pacheco, 2006, p. 142). Após a implementação deste projeto, de forma experimental em três estabelecimentos públicos de ensino em
Lisboa, o Instituto de Apoio à Criança, por meio da criação dos Gabinetes de Apoio ao Aluno e à Família nas Escolas e na Comunidade (GAAF), lançou um projeto semelhante que tem por fim lançar um olhar mais harmonioso sobre as situações de risco das crianças e jovens, nomeadamente as que envolve o contexto escolar.

A mediação escolar surge no início da década de 80 do século passado, em 1982, em São Francisco, nos Estados Unidos (EUA), nos Community Boards que, em comunhão com os centros de mediação comunitária e os sistemas escolares, fazem surgir o programa Recursos de Resolução de Conflitos para a Escola e Jovens. Dois anos depois, nasce, naquele mesmo país, a NAME (Associação Nacional de Mediação Escolar), que tinha por escopo o estudo e implementação da mediação. No ano seguinte, esta Associação se funde com o Litígios), surgindo a CRENET (Rede de Resolução de Conflitos na Educação). Posteriormente, estes programas expandiram-se para 0 mundo, sendo fortemente aplicados no Brasil, Argentina, Nova Zelândia, Canadá, França, entre outros (Tomás, 2010, p. 29).

A mediação escolar segue os mesmos princípios da mediação comum, sendo um processo voluntário, confidencial, flexível, levado a cabo por um mediador, neutro, que, por meio de técnicas de escuta, comunicação e negociação, promove a comunicação rompida, auxiliando as partes a eventualmente caminharem para um acordo, mas sobretudo para um melhor nível de diálogo, compreensão e empatia. 
também pedagógica para toda a comunidade, pois, como afirma Tomás (2010, p. 32)

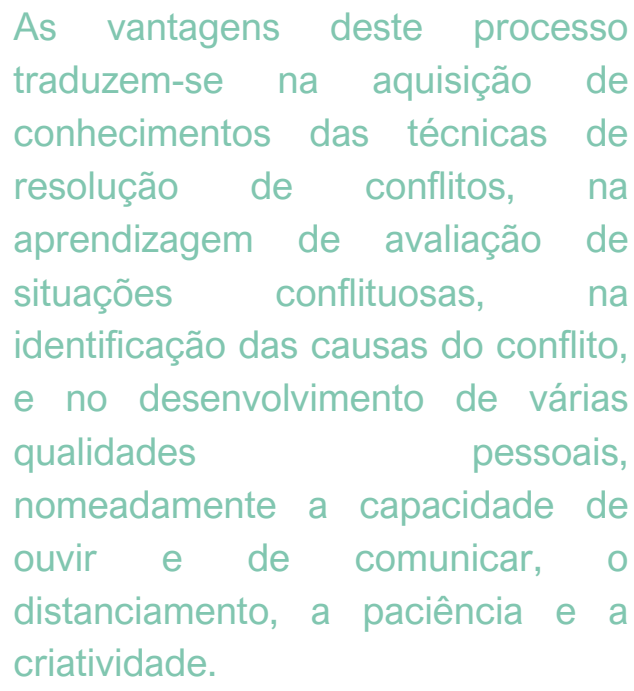

A mediação escolar possui objetivos relacionados não só a mediação de conflitos em si, mas também intenta auxiliar o corpo discente em suas demandas, como prevenir situações de risco, colaborar no desenvolvimento pessoal e social do aluno, promover ações de integração e inclusão, contribuir com os jovens em tomadas de decisões.

E como se pode promover a mediação na escola? Deve-se propiciar espaços neutros, sistêmicos, informais e mesmo pedagógicos, onde todos os intervenientes possam participar, (re)construindo um diálogo e formando uma nova cultura no sentido da paz.

Os alunos devem ser formados como mediadores, bem como os professores, pois estes irão coordenar o trabalho, para além dos funcionários da escola, para que assim estejam aptos a uma forma de administração de conflitos mais positiva e eficaz, sobretudo a longo prazo, em detrimento de medidas meramente punitivas ou ditas preventivas, quando se sabe que pouco há de prevenção nessa disciplinação. Assim, pode-se pensar, inclusive, em equipas de mediadores. No entanto, ao se preparar um projeto para uma escola, deve ser analisado o contexto da mesma e verificar as reais necessidades, em termos de tipos de conflitos, que tem aquele ambiente escolar. Enfim, é importante a participação de toda a comunidade, isto é, que a mesma esteja integralmente representada.

De acordo com Pacheco (2006, p. 173), "o principal objectivo da mediação escolar é a aquisição, manutenção e generalização de uma intervenção comportamental/cognitiva, no sentido da prevenção e remediação dos comportamentos disruptivos ou agressivos nas escolas".

Dentro dos projetos de mediação escolar, os mediadores podem ser, como já mencionado, os próprios alunos, inclusive, recebendo a formação adequada para tanto. Interessante, em um ambiente escolar, começar pelos alunos mais velhos como mediadores, posto que são, via de regra, os exemplos, os modelos seguidos pelos alunos mais jovens, não obstante estas práticas possam (e devam) até ser levadas a ambientes de pré-escola, onde as crianças, que também passam por conflitos, mas ainda não tem o ego a imperar, a dominar, e, portanto, mais facilmente assimilam a nova forma de comunicação e de administração de conflito. Tudo dependerá do que aquela escola ou aquele caso em particular necessita, pois podemos ter conflitos entre alunos, entre alunos e adultos e entre adultos somente (Morgado e Oliveira, 2009, p. 43), sendo por esta razão necessário, como acima afirmado, que haja representante de cada um dos atores da comunidade como mediadores.

Pacheco (2006, p. 182) afirma que a mediação por pares deve obedecer a 
seguinte estrutura para ser dinamizada em uma escola:

\section{Sensibilização da comunidade educativa \\ 2. Formação de professores \\ 3. Sensibilização dos alunos, pelo respectivo Director de Turma, na aula de Formação Cívica \\ 4. Distribuição e preenchimento de questionários (sobre a tipologia de conflitos existente na escola e respectivas estratégias de resolução utilizadas e/ou a utilizar) \\ 5. Abertura de concurso para mediadores \\ 6. Selecção dos alunos para mediadores \\ 7. Formação de alunos \\ 8. Constituição de equipas de mediadores \\ 9. Abertura do Gabinete de Mediação \\ 10. Acompanhamento da Mediação \\ 11. Comunicação/partilha de resultados}

Morgado e Oliveira (2009, p. 50) afirmam que a apesar de a mediação por pares se mostrar bastante eficiente, os benefícios são ainda maiores quando "mediação inclui não só crianças e jovens, como pais, educadores e restante pessoal escolar e da comunidade".

Ao iniciar o processo de mediação, o mediador esclarece todos os pontos que ali irão ocorrer, as regras a seguir, os princípios que regem a mediação, estabelece os parâmetros da comunicação (respeitosa, empática), tentando dissolver a tensão e a desconfiança mútua, e pode ajudar os mediandos a compreender o contexto que os levou ao conflito, dando destaque aos elementos mais importantes daquilo que for sendo trazido, bem como direcionar as partes para os pontos convergentes, isto é, para as áreas de consenso, nas quais os interesses comuns se sobressaem, de modo a que propostas criativas surjam em direção a um possível acordo. O mediador pode lançar mão de várias técnicas para instrumentalizar o processo, sendo certo que não tratarei dessas técnicas aqui por não serem o objetivo deste texto.

A abordagem da intervenção pode ser individual ou em grupo, sendo sempre avaliado de acordo com a dinâmica da escola e da questão com a qual está se lidando, podendo ainda se elaborar programas para melhoria de competências pessoais. $\mathrm{O}$ mais importante aqui é o saber ouvir, sem julgamentos, sem preconceitos. O estar aberto ao que o outro tem a dizer; às suas necessidades e interesses, colocando de lado seu ego, seus temores iniciais, sendo o mediador aquele que ajudará as partes a "baixar a guarda", para que esta escuta seja empática. E este saber ouvir é não só ao outro, mas também a si próprio.

Vivemos hoje uma cultura da violência, um discurso do ódio, que deve ser rapidamente substituído por uma cultura de paz. Nesse aspecto a mediação escolar poderá contribuir para uma transformação em relação à forma como se encara e se lida com os conflitos que surgem na escola e que vão surgir no decorrer da vida, significando que os resultados da mediação ultrapassam os muros da escola.

Assim, verifica-se que o processo de mediação no âmbito escolar traz inúmeras vantagens à toda comunidade, incluindo benefícios pedagógicos, pois a criança ou o jovem adquirem novas competências para a sua vida. Aprendem a falar com 
respeito e a ouvir com empatia, aprendem a gerir as suas próprias emoções também, pois quando estamos em um conflito, gatinhos emocionais já foram e são constantemente disparados, sendo necessário abrandar suas emoções menos boas, acalmar seu ego e deixar fluir a comunicação empática entre as partes em litígio.

Pacheco (2006, p. 196) afirma que estes benefícios igualmente se refletem no contexto familiar, na medida em que as crianças e os jovens passam a "lidar com o conflito de forma construtiva, conduzem a sua vivência quotidiana de tal forma que levam os outros elementos da sua família a uma maior compreensão e cooperação na resolução dos hipotéticos conflitos familiares".

Aprendem, na verdade, que há uma nova forma de se comunicar de se lidar com o conflito, e que estas vertentes não necessariamente passam pela disciplinação, violência e punição. Antes pelo contrário, pois a comunicação empática, promovida por uma escuta ativa, é o reverso desta carta. Vale a pena mencionar a Comunicação Não Violenta como um importante instrumento para materializar este objetivo.

\section{Conclusão}

Florinda Pacheco aduz que há inúmeros efeitos positivos da mediação escolar sobre os alunos, identificando alguns como:

\section{aprende a lidar com o conflito de forma construtiva, atribui real valor à comunicação efectiva, gere as suas percepções de maneira menos conflituosa, compreende as razões da diferença, altera-se o modo de encarar a realidade, ultrapassa mais facilmente os conflitos gerados pelas relações humanas (Pacheco, 2006, p. 190).}

Com a mediação escolar estaremos diante mais do que uma administração de conflito, mas uma educação para a administração de conflito, na qual as crianças e jovens passam a adquirir uma série de competências e valores que serão de enorme importância para sua vida e para seu desenvolvimento enquanto ser.
Passarão a encarar o conflito sob uma nova ótica, a identificar seus gatilhos mentais que disparam os conflitos, a gerir as suas emoções. Enfim, tudo isso afasta mais e mais a cultura da violência, tão impregnada em nossa sociedade atual.

Uma sociedade na qual as crianças e jovens, desde cedo, em seus bancos escolares aprendam a administrar seus conflitos e escolas que compreendam esta dimensão do conflito não de forma negativa e punitivista, mas sim dentro de um clima comunicacional empático entre todos os atores sociais, de modo que esta população infanto-juvenil se desenvolva e se conduza com um novo olhar sob os conflitos, sobre os outros, pois aprendeu a ser empático, terá enormes ganhos democráticos, emancipatórios, tendo como norte a construção de uma cultura de/educação para a paz. 

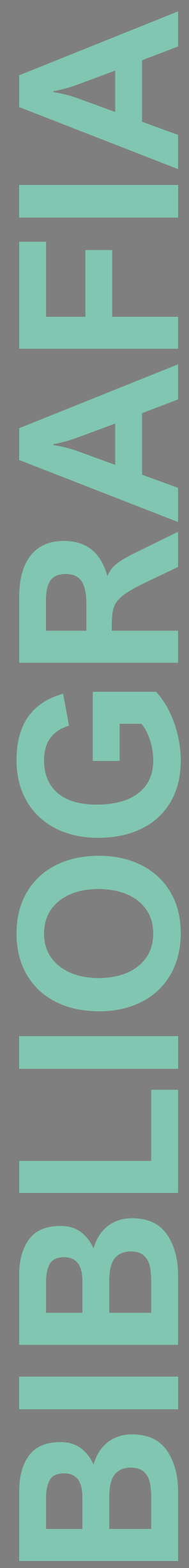

ANDRADE, V.R.P. (2004). Do Paradigma etiológico ao paradigma da reação social: Mudança e permanência de paradigmas criminológicos na ciência e no senso comum. Revista Sequência 30. págs. 24 a 36.

BARATTA, A. (1994) Filósofo de uma Criminologia Crítica. In. Mídia e Violência Urbana. Rio de Janeiro: Faperj.

BARATTA, A. (1999). Criminologia Crítica e a Crítica da Criminologia, Rio de Janeiro: Freitas Bastos.

BENTO, A.C. (2017). O programa Escola Segura: prevenção, proximidade e comunidade. Etnográfica, Lisboa, v. $21, \quad$ n. 2, p. 319-339, jun. Disponivel em $<$ http://www.scielo.mec.pt/scielo.php?script=sci_arttext\&pid=S0 873-65612017000200005\&lng=pt\&nrm=iso>. acesso em 16 maio 2020.

DIAS, M.T.F. (2016). A mediação na Administração Pública e os novos caminhos para a solução de problemas e controvérsias no setor público. Revista online Direito do Estado. N. ${ }^{\circ} \quad 151 . \quad$ Ano $2016 . \quad$ Disponível em http://www.direitodoestado.com.br/colunistas/maria-terezafonseca-dias/a-mediacao-na-administracao-publica-e-os-novoscaminhos-para-a-solucao-de-problemas-e-controversias-nosetor-publico. Acesso em 17 de maio de 2020.

FISHER, R.; URY, W.; PATTON, B. (2014). Como chegar ao sim: como negociar acordos sem fazer concessões. $3^{a}$ edição. Rio de Janeiro: Solomon.

FOUCAULT, M. (1987). Vigiar e Punir: nascimento da prisão. Trad.: Raquel Ramalhete. Petrópolis, Ed. Vozes. 288p.

LUSA (2020). Violência nas escolas em Portugal: todas as semanas alguém é agredido ou ameaçado de morte. Jornal Lusa. Disponível em https://24.sapo.pt/atualidade/artigos/em-portugalmais-de-20-escolas-sao-palco-de-agressoes-e-ameacas-demorte. Acedida em 15 de maio de 2020.

MORGADO, C. \& OLIVEIRA, I. (2009). Mediação em contexto escolar. Exedra. V. 1. Jun. Pp. 43-56

PACHECO, F.M.C. (2006). A gestão de conflitos na escola: a mediação como alternativa. Dissertação de Mestrado em Administração e Gestão Educacional. Lisboa.

REIS, C. (2019). A empatia na mediação: a contribuição da comunicação não violenta. Revista J2. V.2, n.1. DOI: https://doi.org/10.29073/j2.v2i1.194

SIMMEL, G. (1983) A natureza sociológica do conflito, in Moraes Filho, Evaristo (org.), Simmel, São Paulo, Ática.

TOMÁS, C. A. R. (2010) Mediação escolar - para uma gestão positiva dos conflitos. Relatório de estágio do Mestrado 

Jornal Jurídico 